\title{
Occurrence data of large branchiopods in the Northern Western Ghats, India
}

Sameer Padhye (D) \& Mihir Kulkarni
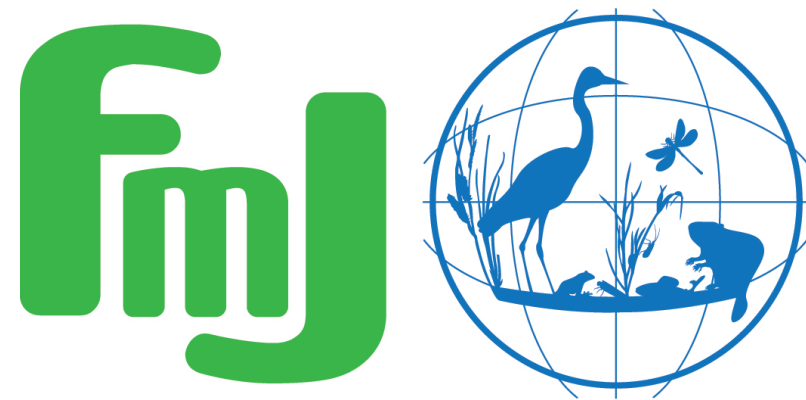

Freshwater Metadata Journal 



\title{
Occurrence data of large branchiopods in the Northern Western Ghats, India
}

\author{
Sameer Padhye ${ }^{1}$ (iD) \& Mihir Kulkarni ${ }^{2}$ \\ 1 Systematics, Ecology \& Conservation Lab, Zoo Outreach Organization, Coimbatore, India; corresponding author: \\ sameer.m.padhye@gmail.com \\ 2 Department of Zoology, Savitribai Phule Pune University, Pune, India
}

Please cite this paper as follows: Padhye, S.M.P. \& Kulkarni, M.R.K., 2019. Occurrence data of large branchiopods in the Northern Western Ghats, India. Freshwater Metadata Journal 41: 1-6.

https://doi.org/10.15504/fmj.2019.41

Received: 2019-02-21 / Published: 2019-02-22

\section{Keywords}

Western Ghats, Rock pools, Crustacea, Anostraca, Notostraca, Spinicaudata, Streptocephalus, Triops

\section{Short description of the dataset/summary}

The field data provide species distribution records of a crustacean group called the large branchiopods from some freshwater habitats in the Western Ghats of India. Species occurrence data have been collected from the year 2009 until 2017 at 45 different localities by means of qualitative sampling using a hand net of $150 \mu \mathrm{m}$ mesh. Data include species name and occurrence records with name, GIS information and waterbody type of the sampled locality. A total of 12 species from 5 different orders which includes three new endemic species and two distinct populations are reported from a total of 90 samples (Rogers and Padhye 2014, 2015; Padhye and Dahanukar, 2015; Padhye and Ghate 2016; Padhye and Kulkarni, 2017; Padhye et al. 2015, 2016, 2018). All the three endemic species have a geographically restricted range with one species, Leptestheria gurneyi known only from its type locality till date. These data, therefore, provide baseline information for future biodiversity conservation planning and management of the habitats as well as the species.

\section{General information}

dataset entry ID:

name of the dataset:

full name of the dataset:

dataset short name:

type of dataset:

data type:
FWM_21

Occurrence data of large branchiopods in the Northern Western Ghats, India Branchiopod occurrence data in Western Ghats, Indi species distribution data point data/observation data

science keywords according to GCMD:

topic:

Terrestrial Hydrosphere

ISO topic category according to ISO 19115:

Biota, Inland Waters 


\section{INSPIRE keywords according to GEMET:}

Species distribution

own science keywords:

Indian subcontinent, rocky outcrops, Anostraca, Notostraca, Spinicaudata, Laevicaudata, freshwater

funding:

The initial part of the field work was carried out from the funds provided by

CSIR-India PhD scholarship.

\section{Technical and administrative specifications}

$\begin{array}{ll}\text { data format: } & \text { Excel } \\ \text { operating system: } & \text { Win 8/8.1 } \\ \text { data language: } & \text { English } \\ \text { current access level: } & \text { web (public) } \\ \quad \text { currently available through GBIF: } & \text { no } \\ \text { exchange planned: } & \text { yes } \\ \text { data in data repository: } & \text { no }\end{array}$

Do you plan to publish the data on the Freshwater Biodiversity Data Portal:

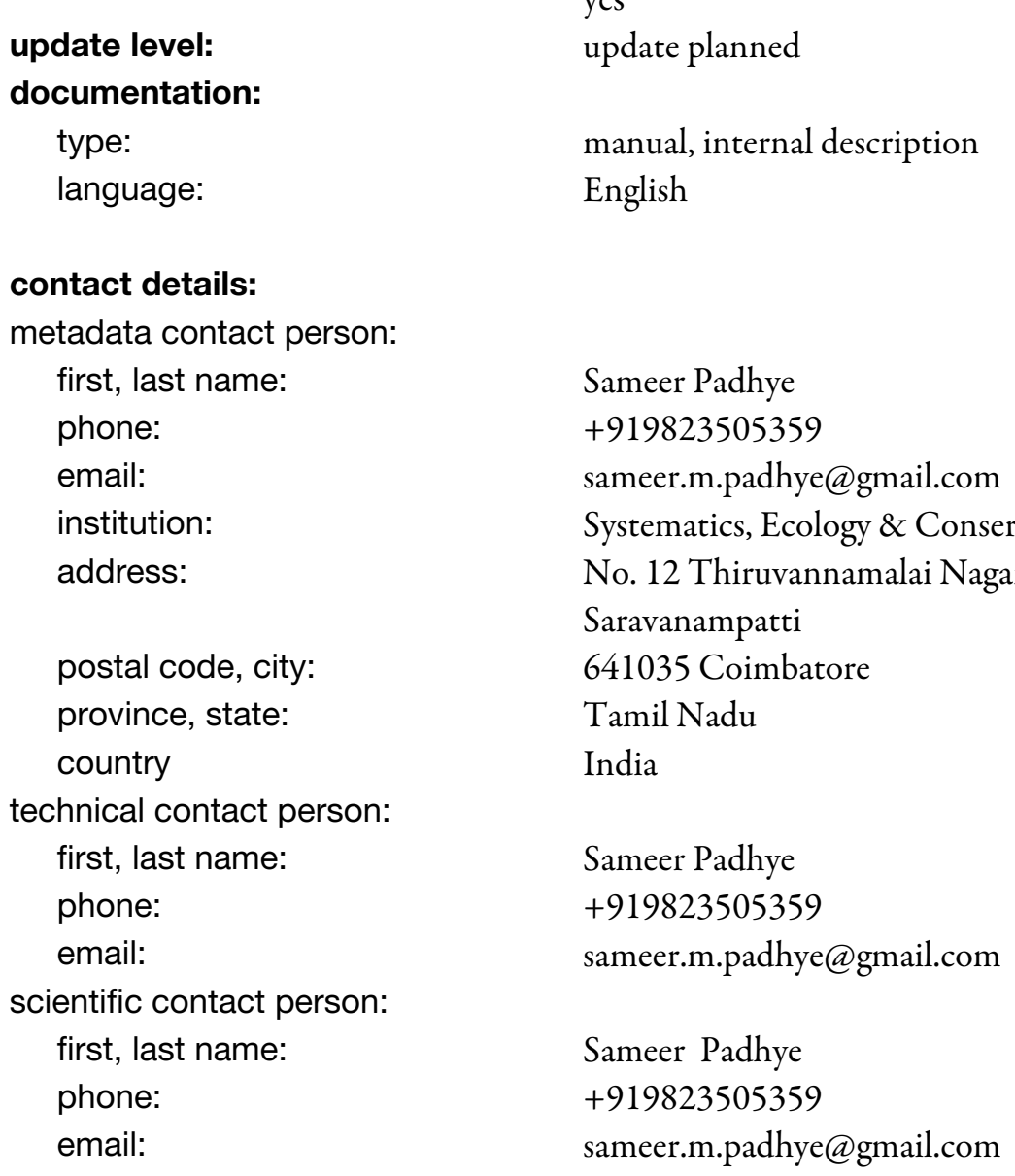

\section{Intellectual property rights and citation}

\section{dataset creator (data compiler):}

contact name:

contact email:

contact institution:
Sameer M. Padhye

sameer.m.padhye@gmail.com

Systematics, Ecology \& Conservation Lab, Zoo Outreach Organization 
data contributors to/owners of this dataset:

multiple

number:

2

data contributor/owner 1:

contact name:

Sameer M. Padhye

contact email:

contact institute:

sameer.m.padhye@gmail.com

Systematics, Ecology \& Conservation Lab, Zoo Outreach Organization

criteria for using this part of the dataset:

The dataset is publicly available (data portal, data archive) and can be used without restrictions, but must be acknowledged and cited correctly.

data contributor/owner 2:

contact name:

Mihir R. Kulkarni

contact email:

mihircoolkarni@gmail.com

contact institute:

criteria for using this part of the dataset:

Department of Zoology, Savitribai Phule Pune University

The dataset is publicly available (data portal, data archive) and can be used without restrictions, but must be acknowledged and cited correctly.

citation of this dataset:

author(s):

Padhye, S.M. \& Kulkarni, M.R.

title and journal (name, number, pages):

Large Branchiopoda occurrence data (2009-2017) in the Northern Western

Ghats, India.

year: 2019

doi: $\quad$ https://doi.org/10.15468/vpaw3g

citation of the metadata:

author(s): $\quad$ Padhye S.M.P. \& Kulkarni M.R.K.

title and journal (name, number, pages):

Occurrence data of large branchiopods in the Northern Western Ghats, India.

Freshwater Metadata Journal 41: 1-6

year:

2019

doi:

https://doi.org/10.15504/fmi.2019.41

\section{dataset related references:}

reference 1:

author(s):

title:

year:

doi:

Rogers, C. \& Padhye, S.M.

A new species of Streptocephalus (Crustacea: Anostraca: Streptocephalidae) from the Western Ghats, India, with a key to the Asian species. Zootaxa 3802

(1): 075-084.

2014

https://doi.org/10.11646/zootaxa.3802.1.6

reference 2:

author(s):

title:

Padhye, S.M., Rabet, N. \& Ghate, H.V.

First faunal inventory of large branchiopods (Crustacea: Branchiopoda) of Western Maharashtra, India with taxonomical and distributional comments.

Zootaxa 3904 (2): 208-222.

year: 2015

doi: $\quad$ https://doi.org/10.11646/zootaxa.3904.2.2

reference 3:

author(s): $\quad$ Padhye, S.M. \& Dahanukar, N.

title:

Distribution and assemblages of large branchiopods (Crustacea: Branchiopoda) of northern Western Ghats, India. Journal of Limnology 74(2): 371-380. 
year:

doi:

reference 4:

author(s):

title:

year:

doi:

reference 5:

author(s):

title:

year:

doi:

reference 6:

author(s):

title:

year:

doi:

reference 7:

author(s):

title:

year:

doi:

reference 8:

author(s):

title:

year:

doi:
2015

https://doi.org/10.4081/jlimnol.2015.1115

Padhye, S.M. \& Ghate, H.V.

Description of a new species of the genus Leptestheria (Crustacea:

Branchiopoda: Spinicaudata) from Western Ghats, Maharashtra, India. Zootaxa 4127(2): 345-354.

2016

https://doi.org/10.11646/zootaxa.4127.2.6

Padhye, S.M., Timms, B. \& Ghate, H.V.

Large branchiopod (Crustacea: Branchiopoda) egg morphology of Western Ghats, Maharashtra, India. Zootaxa 4079 (2): 246-254.

2016

https://doi.org/10.11646/zootaxa.4079.2.6

Padhye, S.M. \& Kulkarni, M.R.

A new Indian record and morphological variation for Eulimnadia khoratensis Rogers et al., 2016 (Crustacea: Branchiopoda: Spinicaudata). Zootaxa 4268 (1): $147-150$.

2017

https://doi.org/10.11646/zootaxa.4268.1.10

Padhye, S.M., Rabet, N., Kulkarni, M.R. \& Pagni, M.

A new species of genus Eulimnadia Packard, 1874 (Branchiopoda: Spinicaudata: Limnadiidae) from India with an updated key for some Indian species.

2018

https://doi.org/10.11646/zootaxa.4399.3.4

Rogers, D. C., \& Padhye, S.M.

Review of the large branchiopod crustacean fauna of the Indian Subcontinent (Anostraca, Notostraca, Laevicaudata, Spinicaudata, Cyclestherida). Journal of Crustacean Biology, 35(3), 392-406.

2015

https://doi.org/10.1163/1937240X-00002327

\section{General data specifications}

regional coverage of the dataset:

spatial extent of the dataset:

regional

continents:

Asia

countries:

Asia: India

world climatic regions according to Köppen:

Group A: tropical/megathermal climates

Group B: dry (arid and semiarid) climates

freshwater ecoregions of the world (FEOW) according to WWF:

ecosystem type:

covered timeframe:
Asia: Northern Deccan Plateau, Western Ghats rivers, lakes/ponds, wetlands, general freshwater 2009 - 2017 


\section{Site specifications}

coordinate system/grid data:

grid data available:

site coding available:

number of sites:

exact number of sites:

\section{Biological data}

biological data origin:

organism group addressed: latitude/longitude, format: DD

no

no

$<100$

90

from sampling,

Taxonomy and Systematics of the 'Large Branchiopoda' (Crustacea:

Branchiopoda) of the Indian Subcontinent

other group(s): Anostraca, Notostraca, Spinicaudata, Laevicaudata, Cyclestherida

\section{Sample resolution}

\section{other group(s):}

taxonomic resolution:
level:
genus, species

percentage of species level data: 100

taxonomic coding:

taxalist according to:

Rogers \& Padhye (2015)

reference(s):

Rogers, D.C. \& Padhye, S. (2015). Review of the large branchiopod crustacean fauna of the Indian Subcontinent (Anostraca, Notostraca, Laevicaudata, Spinicaudata, Cyclestherida). Journal of Crustacean Biology, 35(3): 392-406.

sample specifications:

specification of method(s) used for sampling and sorting:

A qualitative representative sampling of each habitat was carried out using a

hand net having a mesh of 150 micrometers. Samples were immediately preserved in $8 \%$ formalin in the field.

\section{Other specifications}

\section{GIS layers, shape files related to the dataset:}

\section{availability of photos:}

species distribution

availability of maps:

no

no

quality control procedures:

Were any quality control procedures applied to your dataset? 


\section{References}

Padhye, S.M. \& Dahanukar, N., 2015. Distribution and assemblages of large branchiopods (Crustacea: Branchiopoda) of northern Western Ghats, India. Journal of Limnology 74(2): 371-380. https://doi.org/10.4081/jlimnol.2015.1115

Padhye, S.M. \& Ghate, H.V., 2016. Description of a new species of the genus Leptestheria (Crustacea: Branchiopoda: Spinicaudata) from Western Ghats, Maharashtra, India. Zootaxa 4127(2): 345-354. https://doi.org/10.11646/zootaxa.4127.2.6

Padhye, S.M. \& Kulkarni, M.R., 2017. A new Indian record and morphological variation for Eulimnadia khoratensis Rogers et al., 2016 (Crustacea: Branchiopoda: Spinicaudata). Zootaxa 4268 (1): 147-150. https://doi.org/10.11646/zootaxa.4268.1.10

Padhye, S.M., Rabet, N. \& Ghate, H.V., 2015. First faunal inventory of large branchiopods (Crustacea: Branchiopoda) of Western Maharashtra, India with taxonomical and distributional comments. Zootaxa 3904 (2): 208-222. https://doi.org/10.11646/zootaxa.3904.2.2

Padhye, S.M., Rabet, N., Kulkarni, M.R. \& Pagni, M., 2018. A new species of genus Eulimnadia Packard, 1874 (Branchiopoda: Spinicaudata: Limnadiidae) from India with an updated key for some Indian species. Zootaxa 4399 (3): 341-350. https://doi.org/10.11646/zootaxa.4399.3.4

Padhye, S.M., Timms, B. \& Ghate, H.V., 2016. Large branchiopod (Crustacea: Branchiopoda) egg morphology of Western Ghats, Maharashtra, India. Zootaxa 4079 (2): 246-254. https://doi.org/10.11646/zootaxa.4079.2.6

Rogers, C. \& Padhye, S.M., 2014. A new species of Streptocephalus (Crustacea: Anostraca: Streptocephalidae) from the Western Ghats, India, with a key to the Asian species. Zootaxa 3802 (1): 075-084. https://doi.org/10.11646/zootaxa.3802.1.6

Rogers, D.C., \& Padhye, S.M., 2015. Review of the large branchiopod crustacean fauna of the Indian Subcontinent (Anostraca, Notostraca, Laevicaudata, Spinicaudata, Cyclestherida). Journal of Crustacean Biology 35(3): 392-406. https://doi.org/10.1163/1937240X-00002327 